\title{
STUDIES OF THE MORPHOLOGY OF WATERPROOF COATINGS BASED ON URETHANE ISOCYANATE, ALKYL-PHENOL-FORMALDEHYDE RESIN AND DIBUTYLTIN DILAURATE USING THE HIGH-RESOLUTION OPTICAL MICROSCOPY TECHNIQUE
}

\author{
Larisa Matveeva1 ${ }^{1}$ Maria Efremova², Irina Baranets ${ }^{3}$ \\ ${ }^{1,2}$ Saint Petersburg State University of Architecture and Civil Engineering \\ 2-ya Krasnoarmeiskaya st. 4, St. Petersburg, Russia \\ ${ }^{3}$ Research agency of caoutchouc \\ Gapsal'skaya st. 1, St. Petersburg, Russia \\ 1 lar.ma2011@yandex.ru
}

\begin{abstract}
A study of the morphology and structure of waterproof film coatings based on polyurethane isocyanate, alkyl-phenolformaldehyde resin and dibutyltin dilaurate with finely dispersed iron-oxide filler depending on their production method (solution method or melting method) using the high-resolution optical microscopy technique was carried out. When obtaining polymer composites (films), the authors varied the ratio between the main components of the polymer matrix, urethane isocyanate and phenol-formaldehyde resin (1:2 or 1:3), and the content of the finely dispersed iron-oxide filler in relation to the polymer binding medium $(0.1,0.6$ and $1.2 \mathrm{wt} \%)$.

In the modes of bright field, phase contrast and crossed nicols, the homogeneity of the obtained films, their structure, aggregation capacity and distribution uniformity of the powdered iron-oxide filler as a part of the polymer matrix, were investigated.

The obtained composite material in the form of film coating or adhesive repair compound can be used for waterproofing, repairs and corrosion protection as film coatings of water and underwater hydraulic structures.

\section{Keywords}

Waterproof film coatings, urethane polymers and co-polymers, solution and melting methods of film production, ironoxide filler, microscopy, morphology, structure.

\section{Introduction}

Building structures, reinforcement elements and constructions of dams and bridges, supports of submerged pipelines, areas of periodic wetting of port facilities, etc. are constantly subjected to external adverse factors, moisture and water, which contribute to their early destruction (Alkhimenko, Zastrizhnaya, 2016).

It is very important to provide protection of structures against destructive effects of water and moisture at the stage of construction or repair works, as well as during the use of construction facilities. Waterproof coatings made of solid waterproof polymer films, as well as waterproof coating materials and rolled materials are used for this purpose. Works to ensure the safety of structures through overhaul are constantly performed at most important hydraulic facilities (Baydukov, 2017; Balakin et al., 2017; Matveeva et al., 2016). Depending on the conditions of

operation and purpose of structures, various waterproof materials creating a solid and reliable waterproof layer are used to protect the facility against destruction. In building structures, waterproofing protects external surfaces of walls, foundations, basements and underground structures contacting with water or soil. Underwater sections of hydraulic facilities and structures in constant contact with water are of special concern and need special protection.

To perform repair and restoration works (sealing of cracks and joints of structures, repair and arrangement of an additional protective layer, etc.), it is important to select proper materials. There is a number of requirements to properties of materials. First of all, those are: high adhesion, compatibility with old materials, ability to solidify under water, corrosion stability, cold-resistance, waterproofing, strength, resistance to shrinkage and some other properties.
\end{abstract}


New effective materials and techniques of their use allow not only extending the operational lifetime of built hydraulic structures, but also designing and constructing concrete and reinforced-concrete facilities with significantly extended operational lifetime and less operating costs (Matveeva et al., 2016, Belan, 2017; Scientific \& Production Center for Materials and Additives, 2017).

Polymer film materials and coatings based on such materials belong to the category of penetrating waterproof materials. In most cases, those are liquid polymer compositions applied to the surface being protected against water to ensure structure waterproofing and sealing.

Polymer compositions based on polyurethanes are the most efficient due to a complex of chemical, as well as physical and mechanical characteristics, adhesion strength, reliability and durability (Matveeva et al., 2016, 2017; Scientific \& Production Center for Materials and Additives, 2017; Meier-Westhues, 2009).

Additional chemical or physical and chemical modification of polyurethane elastomeric materials, as well as co-polymerization with other functional monomers and compounds allows improving the operational characteristics of waterproof polyurethane compounds and extend the scope of their application in construction (Meier-Westhues, 2009; Matveeva et al., 2016).

\section{Experimental procedure}

To obtain protective film coatings, the following primary components of the composite material were used:

- urethane isocyanate (Trifor), oligomeric product produced by the Research Institute of Synthetic Rubber (FGUP NIISK), Saint Petersburg, according to Specification 38.433809-95 (TRF);

- alkyl-phenol-formaldehyde resin (PFR), a product of condensation of liquid alkylphenols with formaldehyde in the alkaline environment; Specification 2228-352092208-96;
- iron-oxide concentrate (IOC) with a mass fraction of Fe2O3of at least 96\%; dispersity - $25 \mu \mathrm{m}$ max; State Standard GOST 18172-80;

- dibutyltin dilaurate (DBTDL), a synthetic organotin compound produced by FOMREZ CATALYST SUL4"; CAS No. 77-58-7. Appearance: light yellow viscous homogeneous liquid, no sediments or foreign substances; mass fraction of tin, \% - 18.2-18.9; at $25-30^{\circ} \mathrm{C}$, viscosity is $35-60 \mathrm{cP}$; density at $20^{\circ} \mathrm{C}-1.05 \mathrm{~g} / \mathrm{cm}^{3}$. DBTDL is used in the catalysis of adhesives, sealing materials and silicone polymers vulcanized at room temperature. It is also often used for polyurethane-based paint systems.

Film coatings represented mixture composites based on urethane isocyanate (Trifor) with 22 wt\% of NCO-groups, alkyl-phenol-formaldehyde resin (PFR), and dibutyltin dilaurate (DBTDL), with iron-oxide finely dispersed filler depending on the ratio of the main components TRF:PFR $-1: 2$ or $1: 3$, and content of the filler IOF $-0.1,0.6$ and $1.2 \mathrm{wt} \%$ in relation to the polymer binding medium.

For studies of the morphology and structure of waterproof film coatings, an instrumental analytical complex based on a research optical microscope Leica $D M-2500$, digital camera with Peltier cooling Leica DFC-420C capturing high-resolution color images, and a special computer station were used. Image capturing, archiving and quantitative processing were performed with the use of the relevant software - Leica Las.

Samples were represented by polymer films with a thickness of $0.25-0.5 \mathrm{~mm}$ laid between the object plate and cover glass. The films were produced by the following methods: 1) solution method, i.e. by combining components in an inert solvent environment; 2) melting method, i.e. preliminary heating until viscosity is reduced and components transfer to a state of viscous flow with subsequent mixing. The samples were studied using the method of high-resolution optical spectroscopy in the transmission mode using bright field, phase contrast and crossed nicols. The study results were obtained as highresolution color microphotographs.

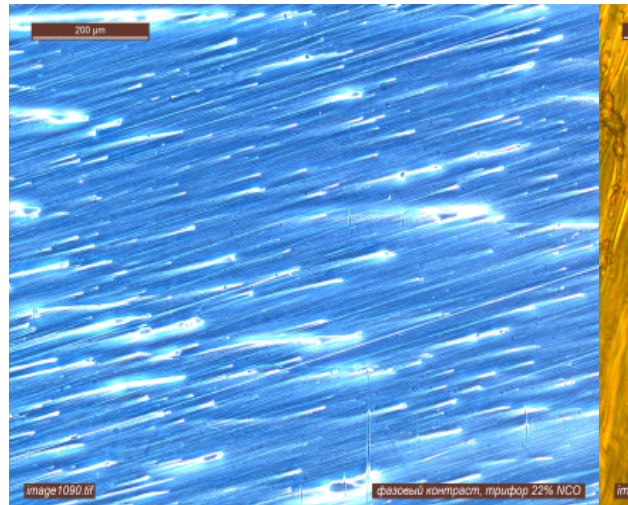

a

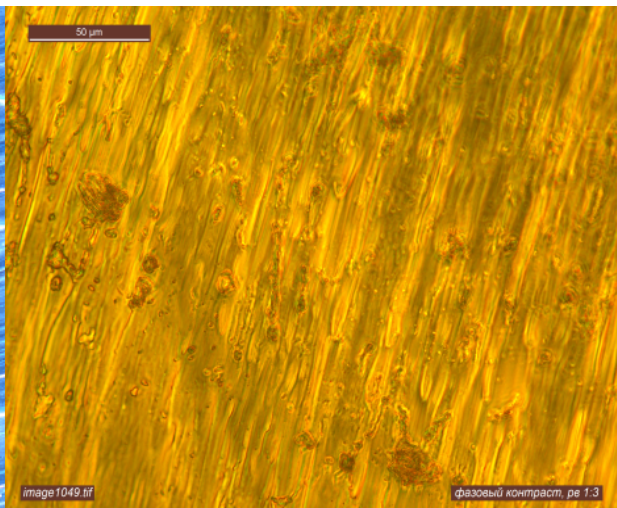

b

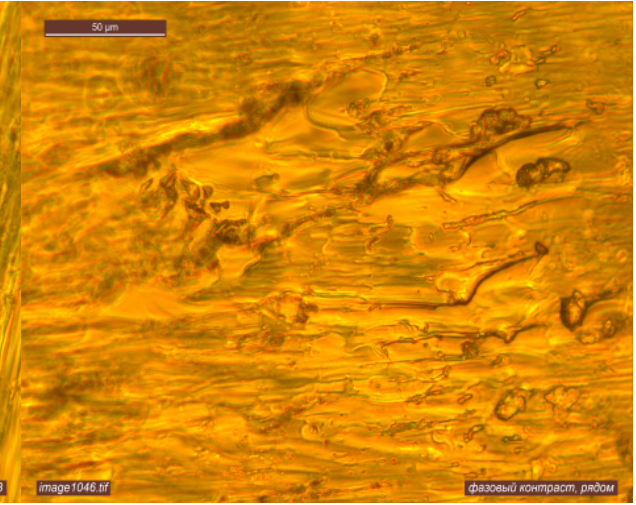

C

Figure 1. a) TRF, phase contrast mode; b) PFR + TRF solution, phase contrast mode; c) PFR + TRF melting, phase contrast mode 


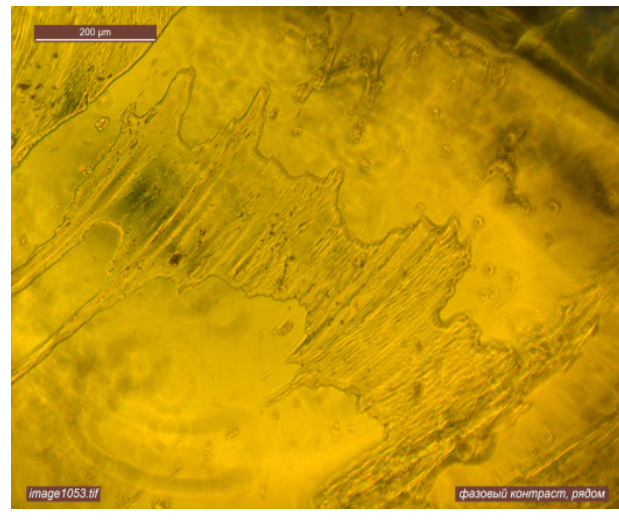

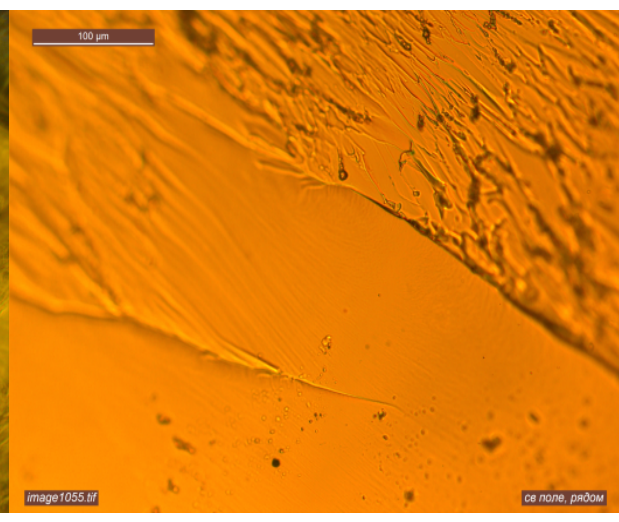

b

Figure 2. Microphotographs of films produced by the melting method: a) phase contrast mode; b) bright field mode

In total, in the course of the study, 66 images (pictures) with a total volume of $632 \mathrm{MB}$ were obtained. They reflected both primary components of the compound and film coatings with various ratio of primary components of the material, obtained using different methods.

\section{Discussion}

The morphology of most mixtures of two polymers depends on the structure of primary components and an interphase transition layer formed as a result of diffusion of macromolecule parts in the polymers in contact. When two polymers are in contact, due to diffusion of individual parts of macromolecules, a transition layer can form. Its thickness depends on the interacting force of component molecules and some other factors.

If the interaction between macromolecules of different polymers is stronger than the forces of intermolecular interaction in individual components, then the probability of the formation of a homogeneous one-phase system with a corresponding technique of mixture production will be rather high.

Otherwise, if the forces of intermolecular interaction of individual parts (components) of molecules are stronger than the forces of interaction between molecules of different polymers in the mixture, then the system will be heterogeneous and two-phase. Completely homogeneous mixtures of polymers are quite rare (Kuleznev, 1980; Tkhakakhov, 2013).

In the course of data processing and analysis, it was established that the main primary component (Trifor) and compounds based on it had a layered structure in the absence of the filler (Figure 1a). Individual internal layers can be easily detected, their sizes are from 0.2 to $5 \mu \mathrm{m}$. The most uniform alteration of PFR and TRF layers is provided by the solution method when films are produced using toluene solvent at the of ratio 1:2 to the total mass of the compound (Figure 1b). In case of the ratio of 1:3, layering of films does not decrease; polymer clots and pile-ups are also observed in the film structure (Figure 1c).

The compounds produced by the melting method are characterized by a noticeable gradient of concentration of primary components throughout the whole volume (Figure 2a, b) as is evidenced by lines and spots, nonhomogeneous in thickness, in optical microphotographs in the phase contrast mode.

Apparently, such method of compound production does not provide uniform distribution of components in the mass and formation of a homogeneous film coating.

The iron-oxide concentrate (IOC), in the absence of binding components, has a finely dispersed structure, with

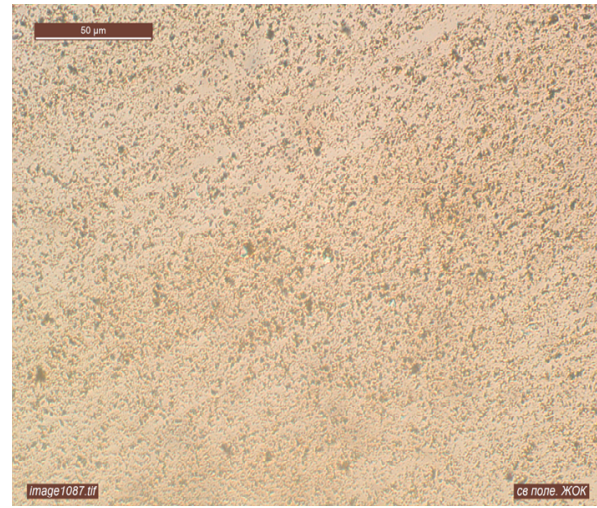

a

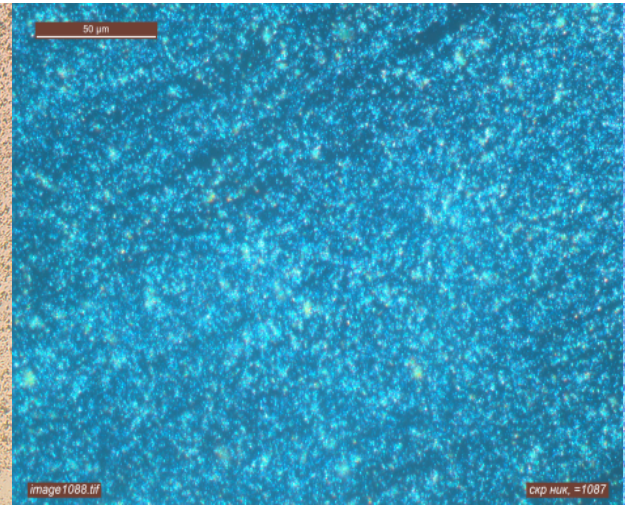

b

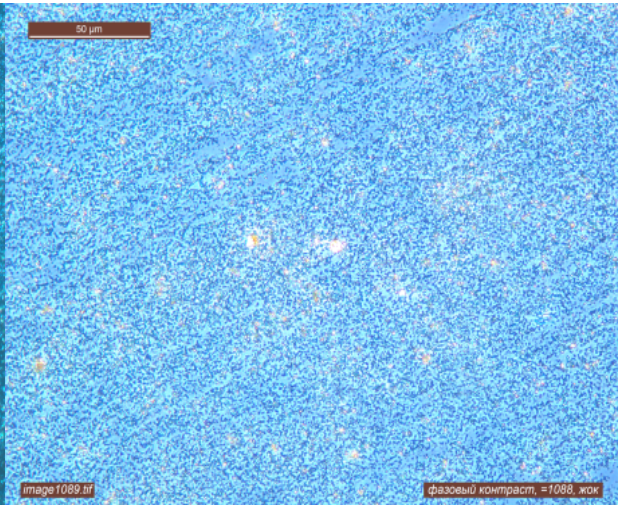

Figure 3. Microphotographs of polymer films filled with the IOC based on PFR + TRF in the mode of: a) bright field); b) crossed nicols; c) phase contrast 
a size of particles of 25-45 $\mu \mathrm{m}$ and low tendency to the formation of aggregates.

Introduction of the IOC into the polymer compound PFR + TRF is accompanied by the increase of the volume fraction and size of the optically dense dispersed phase with apparent diffusion boundaries (Figure $3 a-c)$. The range of aggregate sizes varies from 3 to 108, 120, 343 $\mu \mathrm{m}$ depending on the content of IOC $(0.1,0.6$ and 1.2$)$, respectively.

The studies of waterproof film coatings using the method of high-resolution optical spectroscopy in the transmission mode using bright field, phase contrast, and crossed nicols have shown that the most regular and homogeneous in terms of volume morphological structure of compounds occurs during formation of polymer films by the solution method with the mass ratio of the components PFR:TRF - 1:2.Introduction of the finely dispersed ironoxide filler into the polymer matrix results in the formation of a heterogeneous structure of films with the aggregate sizes from 0.3 to $7 \mu \mathrm{m}$, with the filling degree of $0.6 \mathrm{wt} \%$ (Figure 3a).

The sizes of the dispersed phase increase symbatically with the increase in the content of the iron-oxide filler in the system, distribution of the IOC in the volume of the polymer matrix obtained by the solution method is quite uniform (Figure $3 a-c$ ), and the structure of the film is quite homogeneous.

\section{Conclusions}

As a result of the studies, it has been established that when preparing a waterproof (or adhesive) mixture composite material based on a polymer matrix composed of PFR, TRF and IOC filler, and subsequent formation of film coatings, the solution method shall be preferred. $S$

Since it provides composition which is more homogeneous in volume with relatively uniform distribution of the heterogeneous phase - iron-oxide filler. The optimum ratio of the polymer matrix components PFR + TRF shall be 1:2.

The amount of the iron-oxide filler affects the viscosity (consistence) of the compound and determines the purpose of the compound (covering, adhesive repair, crack sealing compounds, etc.) in the set range of concentrations of 0.1 , 0.6 and $1.2 \mathrm{wt} \%$; the filler is distributed in the volume of the polymer matrix quite uniformly. It can be expected that the distribution uniformity of the compound components and, respectively, the heterogeneity of the formed films will help ensure reliability and sufficiently long operational lifetime of the waterproof protective coating (or adhesive coat) in the conditions of active water environment influence. 


\section{References}

Alkhimenko, A.I., Zastrizhnaya, O.L. (2016). Zashchita morskih i rechnyh gidrotekhnicheskih sooruzhenij ot obledeneniya [Protection of sea and river hydraulic structures against ice formation]. In: Proceedings of the Scientific Forum with Foreign Participants "Polytechnic Week in Saint Petersburg". Saint Petersburg: Peter the Great St. Petersburg Polytechnic University, p.451. (in Russian)

Balakin, D.V., Ermolaev, D.A., Isakov, P.Yu., Karnet, Yu.N. (2017). K voprosu samozalechivaniya treshchin v betonnyh i zhelezobetonnyh plotinah [Concerning crack bridging in concrete and reinforced-concrete Dams]. In: Proceedings of the 11th Scientific and Technical Conference "Water Supply Engineering. Hydraulic Power Engineering. New Developments and Technologies". Saint Petersburg, pp. 21-22. (in Russian)

Baydukov, D.A. (2017). Obespechenie bezopasnosti gidrotekhnicheskih sooruzhenij, raspolozhennyh na territorii SanktPeterburga [Ensuring safety of hydraulic structures located in Saint Petersburg]. In: Proceedings of the 11th Scientific and Technical Conference "Water Supply Engineering. Hydraulic Power Engineering. New Developments and Technologies". Saint Petersburg, p. 20. (in Russian)

Belan, V.I. (2017). Ispol'zovanie kompozicionnyh materialov v stroitel'stve - novyj etap kachestva [Use of composite materials in construction - a new stage in quality]. In: Proceedings of the 11th Scientific and Technical Conference "Water Supply Engineering. Hydraulic Power Engineering. New Developments and Technologies", pp. 27-28. (in Russian)

Kuleznev, V.N. (1980). Smesi polimerov [Polymer mixtures]. Moscow: Khimiya, p.304. (in Russian)

Matveeva, L.Yu. et al. (2016). Innovacionnye pokrytiya dlya zashchity gidrotekhnicheskih sooruzhenij [Innovative coating for protection of hydraulic structure]. In: Proceedings of the 10th Scientific and Technical Conference "Hydraulic Power Engineering. Water Supply Engineering. New Developments and Technologies". Saint Petersburg, p. 157. (in Russian)

Matveeva, L.Yu. et. al., (2016). Dempfernye gidroizoliruyushchie pokrytiya i sostavy «Gidrofor» na osnove poliizocianaturetanov [Damping waterproof coatings and Gidrofor compounds based on polyisocyanate urethanes]. Construction Materials, 7, pp. 63-68. (in Russian)

Matveeva, L.Yu., Efremova, M.A., Shershneva, N.S. (2017). Dempfernye gidroizolyacionnye kompozity na osnove modificirovannyh poliuretanovyh kauchukov [Damping waterproof composites based on modified polyurethane rubbers. Lifecycle of structural materials (from production till recycling)]. In: Proceedings of the 7th All-Russian Scientific and Technical Conference with Foreign Participants, IRKUTSK: Publishing House of the Irkutsk National Research Technical University, pp. 178-185.(in Russian)

Matveeva, L.Yu., Kuksa, P.B., Efremova, M.A., Yastrebinskaya, A.V. (2016). Novye stroitel'nye germetiki s dempfernymi svojstvami na osnove uretanovogo forpolimera [New construction sealants with damping properties based on urethane prepolymer]. Bulletin of the Shukhov Belgorod State Technological University, 12, pp. 206-212. (in Russian)

Meier-Westhues, U. (2009). Poliuretany. Pokrytiya, klei i germetiki [Polyurethanes. Coatings, Adhesives, and Sealants]. Moscow: Payne-Media, p. 400. (in Russian)

Scientific \& Production Center for Materials and Additives (2017). System of materials for construction, waterproofing and repair of concrete. Product Catalog of the Scientific \& Production Center for Materials and Additives. Saint Petersburg, p.223.

Tkhakakhov, R.B. (2013). Morfologiya, processy relaksacii i razrusheniya smesej polimerov raznyh klassov [Morphology, relaxation and destruction processes of mixtures of polymers of various classes]. DSc Thesis in Physics and Mathematics, Nalchik, p.330. (in Russian) 